\title{
The dilemma and coping strategies of local university curriculum construction in the massive open online course era
}

\author{
Baohua Cui \\ Economic Management Department, Jilin Agricultural University, \\ Changchun, China \\ Email: cbhjlau@yeah.net
}

Keywords: MOOC; responding countermeasures; higher education mode

\begin{abstract}
Massive Open Online Courses (MOOC) develop in a rapid pace and quickly spread all over the world. When the learners liarning through MOOC platform, it also exposes more and more problems gradually. In order to promote the development better, faster, more stable of the MOOC, analyses some problems, and exploring and solving strategies in this article.
\end{abstract}

\section{Introduction}

Massive open online course (MOOC)is large-scale network open courses. It is a kind of education form to support large populations for common learning by using education technology and is the teaching process consists of video teaching, stage practice, homework, online interaction, offline discussion and examination and other sections. In fact, MOOC is a wave of revolutionary set off by modern information technology in the field of education that swept through the world and has been widely popular. The main reason for that is its education idea including democratic education and lifelong education and its learning method of autonomous learning and network learning accorded with the current people's psychological needs. However, when we are cheerful and inspiring for the education revolution brought by MOOC, we should also need to think calmly to face the inevitable challenges to higher education.

\section{The reason for MOOC’s being popular}

\section{It meets the need of the current university teaching reform.}

College teaching reform in terms of can be divided into the reform of the teaching content and teaching methods reform from "teaching" aspect. In the university teaching, the most economical, most convenient, most popular is still the one-way transmission type "teaching method". Teachers and students seem to be used to this way of teaching, but the quality of teaching are not so good ${ }^{[1]}$. The MOOC's showing up is undoubtedly an impact again for the traditional teaching methods. It not only changes the teaching and learning mode and program and mobilizes students learning enthusiasm maximumly. This way of teaching really promotes the integration and interaction of teaching and learning and also truly reflects the education concept of student-centered and students' active participation of learning.

\section{It adapts to the information dissemination way in the Internet era.}

The typical feature of Internet age is many-to-many interaction which not only includes the interaction between people, but between human and computer and multiple terminal interaction and also embodies the characteristics of equality and open. This online course mode of MOOC can be regarded as a way of information transmission and learning method which completely accords with the characteristics of the dissemination and access of the Internet. First of all, make the teaching break through time and space limitation so as to let teachers and students can participate easily. Secondly, convenient discussion and free topic on academic ideas can be achieved among students and between teachers and students. Student learning can be more active and more personalized. The last is to use big data analysis and records which can provide better reference for improving the teaching $^{[2]}$. 


\section{It adapts to the function orientation of university.}

University has always been existed as the important carrier of cultural inheritance and the important source of cultural innovation. University with a long history plays an important role in knowledge inheritance and cultural reservation. As a highly open teaching form, MOOC can quickly and effectively expand the university's cultural influence. It not only spreads professional knowledge in some certain field but also inevitably spreads their concepts of education, way of thinking, value system and cultural orientation. Therefore, high-level university participates in the MOOC construction with stronger international awareness and more open field of vision in order to take the advantageous position in the "online education revolution".

\section{The dilemma of local university curriculum construction in the MOCC era}

Course construction has always been the core of university professional construction and talent cultivation. Facing the MOOC wave, national first-level universities have actively participated in MOOC resources construction, aiming to reflect the high-quality curriculum resources. As a not insignificant group among China's higher education army, local universities have to face some embarrassing dilemma. It is more obvious in the understanding and orientation of curriculum construction, the construction ability of curriculum resources, and the effectiveness of the curriculum resource sharing and so on.

The understanding of MOCC construction is unclear and the orientation is not correct.

There are two widespread misunderstanding commonly existed in applied undergraduate colleges and universities to MOCC construction: one is taking and the other is waiting and seeing. As is known to all, it is first-level schools that respond to this newborn thing with the most rapid speed either in worldwide range or in the higher education field in our country who took out the best course resources, in order to expand the demonstration effect of radiation. Any course construction must support professional construction, and professional construction must be subject to the talent cultivation orientation of different types of schools. due to the Local undergraduate colleges and universities just completed or will soon complete the undergraduate course teaching qualified evaluation, they tend to be satisfied with the traditional mode of teaching under the interaction between inertia and inert ${ }^{[3]}$. They adopt the attitude of waiting and seeing for MOCC construction and lack thoughts and ideas to initiatively tackle the impact of MOOC.

\section{Curriculum resources development ability is insufficient.}

In "MOOC era", the curriculum team, huge amounts of teaching resources and timely online interactive learning methods are the inevitable reasons to make the first-level university in the world become the main force for MOOC construction. In China, it is also widely believed in the professional field that top universities are the main body for MOOC construction. Due to the limitation of their own school accumulation and school conditions and other restrictions, the construction ability of MOOC of Local undergraduate colleges and universities is not as good as top universities.

\section{The effectiveness of curriculum resource sharing is not enough.}

At present, the domestic university core curriculum resources are generally concentrated embodied in syllabus, teachers courseware, textbooks, extracurricular reading, and counseling information, etc. by contrast, the curriculum resources released in the MOCC platform are more extensive, which not only includes interactive learning and curriculum evaluation but also covers the vast amount of information on the Internet. Although, the MOCC resources are more abundant, there still exists the problem of "course resources sharing mechanism is not sound and resource utilization is inefficient". 


\section{The coping strategies of local university curriculum construction in the MOOC era}

\section{Accelerate the construction of applied high quality curriculum resources.}

Generally speaking, local university is to cultivate applied talents, which means to train and develop talents to be responsible for production, management, service of the front line and to solve the key technical problems. MOOC takes sharing quality education resources as the premise but also has an identifying and choice on what is high quality education resources. The most suitable is the best quality. So far, the courses developed by MOOC are indeed the high quality education resources, but there is few applied curriculum resources which can be suitable for China's reality. Applied talents are just recognized and appreciated by people, therefore, the applied undergraduate course construction has been attached too much importance by universities and has published some application materials, but there is still a very long way to achieve high quality applied courses. Challenges are often with opportunities and few applied high quality education resources are both a disadvantage and an opportunity for local colleges. If we can combine the characteristics of MOOC and develop practical teaching resources with their own characteristics in the process of applied curriculum construction, we can not only cultivate a large number of excellent teachers but also take the advantage and face the arrival of MOOC leisurely ${ }^{[4]}$. Local competent education manager should fully realize the particularity of practical teaching, publish related policies, formulate qualified teacher implementation plan, and tilt to local applied university in title assessment, quality improvement project, and qualified teacher selection and so on. Local applied universities should possess the consciousness of cultivating qualified teachers and strength the support to potential teachers and attach great importance to policy, capital, and studying.

\section{Reform the traditional teaching mode.}

MOOC is not only about the sharing of high quality education resources outside the campus but also about the discussion on "teaching reform and new teaching mode". Applied talents emphasize students' ability training and ability is fostered through practice. MOOC is a kind of new teaching mode that students choose courses that are suitable for themselves through Internet and study independently before class, discuss with teachers in class and summarize the learned knowledge after class. It is also a kind of autonomous learning process on the Internet. MOOC is to choose teacher, school, and class needed for students in a "massive online classrooms" in which students have greater degrees of freedom and wider choice. Local universities need to discuss the teaching mode of MOOC deeply. On the one hand, it serves for the current teaching; on the other hand, it also provides teaching resources for applied MOOC teaching. With the emergence of MOOC, MOOC can be combined with flip class and students can make use of their spare time to learn courses in famous schools and of qualified teachers on the Internet. They can also have a face-to-face communication and discussion with local teachers and students, which is also a modern teaching mode that is preferable and is beneficial to cultivate students' learning independence and autonomy and improve their learning efficiency ${ }^{[5]}$.

\section{Promote the platform construction.}

The platform construction of MOOC is very important. The three platforms: Coursera、 Udacity、 edX supporting MOOC have their own features respectively. But they are all foreign resources and the domestic Baidu education, netease public courses, cloud, youku are also busy in technology research and development. Local colleges have two choices: one is to study the advantages and disadvantages of these platforms, then choose one which is suitable for them and join in the three "buses" of United Sates; the other one is to establish MOOC education platform with a union nature and encourage applied university with high quality resources to cooperate with external research institutions, education institutions and enterprise. Realize the deep cooperation between applied universities and external institutions, enterprises. Establish a "high-speed rail" suited to the characteristics of the China and serve the MOOC construction of China's applied universities. 


\section{Conclusion}

The emergence of MOOC undoubtedly brings a new wave of education reform and it has caused close attention from all walks of life. It has a huge impetus to the world education reform and evokes people's review of teaching mode. There are also many problems to be solved. Only by keeping discovering problems in the process of application and treading them rationally and correcting them, can MOOC be developed in a better way and the education reform process be steadily push forward.

\section{References}

[1] Fang Xuanxuan. Facing with MOOC: The dilemma and coping strategies of local university. [J]. Journal of Hefei University(Natural Sciences Edition), 2014(2).

[2] Zhang Zhiyuan. The influence of MOOCs on China's higher education and the corresponding coping strategies. [J]. Journal of Hebei Normal University (Educational Sciences Edition), 014(3).

[3] Li Xiaodong. The challenges and countermeasures of MOOC to college teachers' teaching ability. [J]. Journal of Nanjing University of Science and Technology (Social Sciences Edition), 2014(2).

[4] Wang Jing. The SWOT Analysis of MOOC's development in China. [J]. The method of research, 2013(7).

[5] Peking University School of Education. The enlightment of MOOC on higher education reform. [N] .Guangming Journal, $2013-11-18(16)$. 